Article

\title{
Predictability of OTC Option Volatility for Future Stock Volatility
}

\author{
Jungmu Kim ${ }^{1}$ (1) and Yuen Jung Park ${ }^{2, *}$ \\ 1 Department of Business Administration, Yeungnam University, Gyeongsan 38541, Korea; jungmu@yu.ac.kr \\ 2 Department of Finance, College of Business, Hallym University, Chuncheon 24252, Korea \\ * Correspondence: yjpark@hallym.ac.kr; Tel.: +82-33-248-1855
}

Received: 13 May 2020; Accepted: 23 June 2020; Published: 25 June 2020

check for updates

\begin{abstract}
This study explores the information content of the implied volatility inferred from stock index options in the over-the-counter (OTC) market, which has rarely been studied in the literature. Using OTC calls, puts, and straddles on the KOSPI 200 index, we find that implied volatility generally outperforms historical volatility in predicting future realized volatility, although it is not an unbiased estimator. The results are more apparent for options with shorter maturity. However, while implied volatility has strong predictability during normal periods, historical volatility is superior to implied volatility during a period of crisis due to the liquidity contraction of the OTC options market. This finding suggests that the OTC options market can play a role in conveying important information to predict future volatility.
\end{abstract}

Keywords: implied volatility; KOSPI 200 option; over-the-counter; risk management

\section{Introduction}

For sustainable investment in financial assets, the risk and uncertainty of the investment should be properly managed. One of the most important tasks of risk management is volatility forecasting, since volatility is a measure of financial risk and future uncertainty. Therefore, volatility forecasting is crucial for sustainable investment and the management of its risk.

Empirical studies of volatility forecasting have proceeded in two ways. First, historical volatility, which is estimated by using past return data, is used for future volatility forecasting [1-4]. Although some papers [5,6] argue that stock volatility has a unit root (i.e., purely random), and thus it cannot be predicted better than its current level, most of the recent studies on volatility have found that the volatility of stock return is serially correlated and has a mean-reverting property. Thus, volatility forecasting models have been developed based on time-series models, such as the autoregressive conditional heteroscedasticity (ARCH) [7] model and the generalized autoregressive conditional heteroscedasticity $(\mathrm{GARCH})$ [8] model. On the other hand, some papers argue that some variables from other markets where participants are more sophisticated and equipped with better trading skills have more predictive power of future stock volatility. Generally, the options market is regarded as such a market [9-11]. Therefore, many papers [12-15] have investigated the forecasting power in option-implied volatility, which is converted from option prices by the Black-Scholes [16] option pricing model. These papers have found evidence that option-implied volatility can predict future stock volatility better than historical volatility because of informed trading activity.

In line with the second stream, this study also examines whether the information implied by options is more helpful in the prediction of future stock volatility. However, a noticeable distinction between these earlier studies and our study is that we focus on option data traded in the over-the-counter (OTC) market. OTC markets are generally regarded as more efficient in predicting future realized volatility than exchange markets. This is because, while individual investors and domestic and 
overseas institutional investors conduct various types of transactions, such as hedging, speculation, and arbitrage, in the exchange options market, the skilled or institutional investors who prefer anonymity and are supposedly advanced in obtaining and utilizing information, participate mainly in the OTC options market. However, while ample research on the exchange options market exists, there are few studies on the OTC options market, despite its potentially superior efficiency; reviews on some of the papers that analyze the OTC options market are provided in the following section.

In particular, to the best of our knowledge, Yu et al. [17] is the only study that deals with the predictability of OTC stock index options by comparing the information efficiency between the exchange market and the OTC market in Hong Kong and Japan. However, as mentioned earlier, the liquidities of options markets in Hong Kong and Japan are relatively low. In addition, they focus only on the 1-month implied volatility of options. As their sample period covers the time from May 1998 to February 2005, they do not examine the efficiency of the OTC options market during the turmoil period.

Meanwhile, until recently, the exchange-traded KOSPI 200 index options market has been known as the top-tier derivatives market to have the highest trading volume worldwide. Moreover, while the OTC KOSPI 200 index options market is not as liquid as the exchange market, options with relatively longer maturities are traded in this market. Thus, analyzing the OTC KOSPI 200 index options market will provide another important implication for investors participating in the options market.

In this study, we investigate the informative content of the implied volatility extracted from OTC KOSPI 200 stock index options and compare the predictabilities between 1-, 2-, and 3-month implied volatilities. Moreover, we analyze the effect of the global financial crisis on the predictability of the implied volatility. Thus, we address the following research questions: (1) Is the implied volatility of the stock index options traded on the OTC market superior to the historical volatility in forecasting future realized volatility, even in Korea? (2) Does the predictability of the implied volatility differ based on maturity? (3) Does the predictability differ depending on the market conditions?

We define a sustainable market as a financial market where sufficiently many investors participate with a long-term view and informational efficiency is attained because such markets can price assets correctly and provide liquidity for a long time. If we can prove that the OTC options market conveys a better and more information about future spot volatility, compared to stock markets, then the OTC options market can attract more attention and attain more liquidity. In this regard, we argue that information efficiency can help a market be more sustainable. Our finding that the OTC options better predict future volatility than the stock market can contribute to making the OTC options market more sustainable.

The major empirical results of this study are as follows. First, the implied volatility of the OTC KOSPI 200 index options outperforms the historical volatility in explaining future realized volatility, although it is not an unbiased estimator. Secondly, historical volatility has no additional information beyond what the implied volatility already indicates. Thirdly, longer maturities have less predictive power of implied volatility. Finally, when dividing subsamples, while implied volatility has superior predictability during the pre- and post-crisis periods, historical volatility outperforms implied volatility during the crisis period. Therefore, our results provide further evidence of the efficiency of the OTC stock index options market and demonstrate a higher efficiency for options with shorter maturity, and during better market conditions.

Our study makes the following contributions to the literature. First, this is the second study to investigate the efficiency of stock index options traded in the OTC market after Yu et al. [17], who used the Nikkei-225 index and the Hang Seng index options. We confirm the efficiency of OTC index options by using the KOSPI 200 index options. Secondly, while Yu et al. [17] focus on comparing the predictability of the implied volatility of exchange options with that of the OTC options market, our research shows that the efficiency of the OTC stock index options market differs depending on the option's maturity or market conditions. Thirdly, we find that the predictability of the implied volatility of the OTC stock index options is weakened during a crisis period. We explore the liquidity shortage of 
OTC options markets as the possible source of the incapacity of the predictability of implied volatility during the recent global financial crisis.

The findings of our study also provide practical implications to the financial industry because an accurate volatility estimation is a main concern of risk management; Valaskova et al. [18] provide a good review of financial risk management. For example, portfolio managers gauge a potential risk of large losses on their portfolios with Value-at-Risk (VaR). To this end, volatilities of assets are often estimated by using past data. However, one problem is that long time-series data is required to estimate historical volatility reliably and the current change of the market state is difficult to be timely incorporated. The measures estimated by past data smoothly change over time. In contrast, OTC option-implied volatility, a forward-looking measure, is observed at every point of time and can be used to estimate the future volatility. Therefore, the finding that the OTC option-implied volatility forecasts the future spot volatility better than the historical volatility suggests that OTC options markets can provide useful information as a bench-mark to estimate a more accurate VaR.

\section{Literature Review}

\subsection{OTC Options Market}

According to Park et al. [19], in the KOSPI 200 exchange options market over the period 2004-2012, about one-third of the total trading was executed by individual investors, who are generally considered to be speculative, uninformed, and noisy. Notably, about $50 \%$ of the trades were made by individual investors in 2004 and 2005. The KOSPI 200 OTC options are mainly used for hedging structured products, such as Equity Lined Securities (ELSs) issued by institutions. ELSs with long-term maturities also cannot be effectively hedged with only exchange options, which have high liquidity or maturities shorter than 1 month, and thus, the KOSPI 200 OTC options start to be traded as per the needs of institutional investors. Hence, better, more informed professionals trade options in the OTC market. Regarding this, Yu et al. [17], who analyzed the Nikkei-225 index and the Hang Seng index options, also mention that individual investors are the main participants in the exchange market, whereas institutional investors are more likely to participate in the OTC market since it has higher liquidity and anonymity.

However, very few studies, including Yu et al. [17], analyze the OTC options market due to the difficulty in accessing the requisite data. Covrig and Tow [20] examined the predictability of implied volatility for future volatility in the OTC currency options market. Park and Kim [21] examined whether the information embedded in the implied volatility of the OTC put options for individual firms can explain the credit default swap spread. Deuskar et al. [22] analyzed the impact of liquidity on option premiums in the US OTC interest rate options market. Chalamandaris and Tsekrekos [23] explored the OTC currency options surface model. They report that the surfaces implied by 25 different foreign exchange rate options have some factors in common.

\subsection{Option-Implied Information}

Due to the development of the options market, a growing number of papers started to use option information to forecast future spot volatility. There have been a number of papers that investigated the information content in option-implied volatility to forecast future movement of the underlying assets. For example, Manaster and Rendleman [24] provide evidence that the theoretical prices of stocks, derived from option prices by the Black-Scholes option pricing model [16], can predict future stock prices. Doran et al. [25] examined if the option skew, as measured by the volatility difference across various strike prices, can predict stock market crashes. They argue that option volatility could predict future spot prices due to well-informed traders in the options market. Christensen and Prabhala [12] and Fleming [13] found that the implied volatility of the S\&P 100 index option outperforms historical volatility in predicting future realized volatility. Jorion [26] provides evidence that implied volatility is the best volatility forecast using the exchange options on foreign currency futures. Busch et al. [27] 
confirmed the strong forecasting power of implied volatility in the bond, stock, and foreign exchange markets. Taylor et al. [28] also found that the at-the-money implied volatility of individual options is more informative than past volatility for firms with more actively traded options. Xing et al. [29] explored whether the smirk of implied volatility term structure has significant predictive power for future stock returns, when stock options for individual firms are utilized. They show that firms with the steepest smirks tend to experience the worst performance of future stock returns.

Another string of papers focuses on the information content of volatility indices that are generally based on the model-free implied volatility construction. The representative of the volatility indices is the U.S. volatility index (VIX), which is the implied volatility of the S\&P 500 index option with a one-month maturity generated by CBOE. Blair et al. [14] compared the information content of intraday returns and the VIX. They show that implied volatility is superior to high-frequency index returns in forecasting index-realized volatility. Bekaert and Hoerova [30] examined the predictive power of the VIX through decomposition. They decomposed the squared VIX into the conditional stock market variance and the equity variance premium. As a result, they find that the former component predicts economic activities, whereas the latter component predicts stock return. Yun [31] investigated the predictability of the VIX for return and cash flows. He also decomposes the squared VIX into the expected return variation and variance risk premium, and shows that the expected return variation forecasts long- and short-term cash flows while variance risk premium predicts short-term returns.

There are some studies that have used other indices. For example, Luo et al. [32] provide evidence that the CBOE gold ETF volatility index has substantial forecasting power for realized volatility of the Shanghai gold futures market in in-sample and out-of-sample tests. Jung [33] explored the predictability of the Volatility Index of Canada (VIXC) compared with those of GARCH type volatility and found that the VIXC exhibits the worst predictability and GARCH $(1,1)$ makes the best predictions when considering the directional accuracy measured by mean directional error.

Although the S\&P 100 index options have mainly been analyzed, the Korean options market also deserves particular attention. According to Ahn et al. [34], the KOSPI 200 index option is the financial derivative that has been most actively traded in the world. For this reason, a number of papers regarding derivative markets have focused on KOSPI 200 options. For example, Ryu and Yang [35] investigated trading activities depending on the type of investors and found that the trading volume of foreign investors can predict the future movement of the underlying stock index. Kim!and Ryu [36] evaluated the performance of their modified value-at-risk model using Black-Scholes volatility and a volatility index of KOSPI 200 options. Kang and Park [37] found evidence that KOSPI 200 option traders are more skilled than the participants of its corresponding stock market. Chun et al. [38] investigated the forecasting performance of various volatility measures. Their measures include historical volatility, GARCH type volatility, Korea's implied volatility index (VKOSPI), etc. They demonstrate that VKOSPI, which is computed from the market prices of the KOSPI200 options and their underlying index, exhibits the best performance.

Following these studies, we also focus on the KOSPI 200 index option; however, our study deals with the options traded in the OTC market rather than in the exchange, as has been studied by the aforementioned studies. To our knowledge, the KOSPI 200 option traded in the OTC market has never been studied. As explained earlier, OTC option data is likely to convey different and better information about future spot volatility (i.e., KOSPI 200 index volatility). For this reason, our analysis using OTC option data is not redundant considering the existing studies that have examined exchange-traded options.

\section{Data and Methodology}

\subsection{Data}

We collected daily OTC KOSPI 200 index options data for the period from 16 March 2005, to 28 April 2011. The number of institutions offering quotes for OTC stock options has increased recently, 
but only Nittan provides quotes from the early days of the Korean OTC derivatives market. Thus, we use data from Nittan to ensure a sufficient sample period. Access to the OTC market data is very limited and not open to the public. We obtained the data from a market dealer who had collected the trading information. Even though our dataset ends in 2011, the sample period is sufficient to provide general implications and make statistical inferences. Moreover, our sample includes the recent crisis, and a robustness test can be conducted for that period. Therefore, our conclusion is not affected by the characteristics of a particular period.

In the OTC options market, the exercise price is given as a ratio of the current price, and the option price is reported in premium form. We extracted the implied volatility from the option premium based on the Black and Scholes [16] option pricing model. If the traded price exists, we obtain the implied volatility from the traded price; otherwise, we infer the implied volatility from the average of the bid and offer prices. If we have only the bid price, we extract the implied volatility by considering the bid price as the effective price. If we have only the offer price, then we exclude this price from the sample. In addition, we exclude options with a maturity of 7 days or fewer to account for the potential distortion from liquidity risk due to a sharp decrease in trading volume.

Panel A of Table A1 summarizes the number of option quotes for each exercise price range and the days to maturity categories for OTC KOSPI 200 index options. In addition, we divide the options data into call, put, and straddle options. The most noticeable feature of the table is that mid- to long-term options with more than 3 months to maturity are the most common in the OTC market. This is a significant difference from the finding that short-term KOSPI 200 index options with maturities shorter than 2 months are the most common in the exchange market.

The total number of put options was more than that of the call options, and the call options were the most favored at the exercise price of $110 \sim 119 \%$. The put option was most favored at the exercise price of 90 99\%. The call and put options mainly had maturities between 3 months and 1 year. However, most straddle options were quoted within a 100 109\% exercise price range. Straddle option quotes with maturities of over 367 days were large in number; the sample includes over 1600 quotes, which far outnumbers the call or put option quotes with the same expiration range. This means that call or put options are mainly quoted as mid-term and near-the-money, while straddle options are long-term and at-the-money.

Panel B of Table A1 shows the averages of the implied volatilities for each exercise price range and the days to maturity categories for the OTC KOSPI 200 index options. The implied volatility smile, which has a higher implied volatility as it moves away from at-the-money to out-of-the-money, appears for both call and put options. In addition, when we compare the at-the-money options, the implied volatility of the put options was slightly higher than that of the call options, which is similar to most stock index options, such as the S\&P 500 index option and the KOSPI 200 index option traded in the exchange.

\subsection{Estimation of Implied Volatility, Historical Volatility, and Realized Volatility}

To analyze the predictive power of implied volatility, it is appropriate to derive the implied volatilities of the OTC stock index options from at-the-money option prices to reduce the effect of the volatility smile. However, this method would make the sample too small for this study. Hence, we use samples with an exercise price of $80 \sim 120 \%$, which is the near-the-money option range defined by Cao et al. [39], and estimate the implied volatilities according to the Black and Scholes [16] model assumption, and then take their average by applying equal weights across different exercise prices for each maturity.

As Christensen and Prabhala [12] point out, the most important consideration in analyzing the forecasting power of implied volatility is to avoid overlapping data. Thus, we use only options with maturities of 3 months or shorter. In addition, to compare the degree of forecasting power by maturity, we perform a regression analysis for each 1-, 2-, and 3-month maturity options. Further, because the OTC KOSPI 200 option prices contain a sparse sample for fixed short-term maturities, 
we adopt the following method to create non-overlapping data. We construct the time-series of the $1-, 2-$, and 3-month maturities by selecting the options with the longest maturity among those with $8 \sim 31$ (32 62, 63 92) days to maturity at the earliest trading day on each month (odd-month, quarter). We then take the average implied volatilities of the selected options with different exercise prices for each month (odd-month, quarter) to generate the monthly (odd-monthly, quarterly) times-series.

Realized volatility as the dependent variable is calculated from the sample standard deviation of daily log returns of KOSPI200 index prices. Considering the trading days per year, we annualize the sample standard deviation by multiplying the square root of 250 . The historical volatility (realized volatility) refers to the past (future) trading day horizon that corresponds to the average maturity of the selected options; thus, we eliminate the inconsistency in maturity among implied volatility, historical volatility, and realized volatility.

Table 1 reports the summary statistics of implied volatility extracted from KOPSI200 index options quoted in the OTC market, historical volatility, and realized volatility used in the regression analysis. The table shows the averages (Mean) and standard deviations (Std) of the mean, maximum (Max), and minimum (Min). $\mathrm{N}$ denotes the number of time-series data for each maturity. Among them, historical volatility has the smallest mean for 1- and 2-month maturities and realized volatility has the smallest mean for 3-month maturity. For all types of maturity, the mean implied volatilities (about 26 27\%) are higher than the mean realized volatilities (about 21 22\%) by $4 \sim 5 \%$. This suggests that implied volatility is likely to be a biased estimator of realized volatility. This result is similar to the mean bias for the S\&P 500 index options documented by Becker et al. [40] and for the OTC stock index options as reported by Yu et al. [17].

Table 1. Summary statistics of implied volatilities, historical volatilities, and realized volatilities.

\begin{tabular}{lccccccccccccc}
\hline & \multicolumn{4}{c}{ Implied Volatility (\%) } & \multicolumn{3}{c}{ Historical Volatility (\%) } & \multicolumn{3}{c}{ Realized Volatility (\%) } \\
& Mean & Std & Max & Min & Mean & Std & Max & Min & Mean & Std & Max & Min & N \\
\hline $\begin{array}{l}\text { 1-month } \\
\text { maturity }\end{array}$ & 26.3 & 12.8 & 93.4 & 13.8 & 22.4 & 12.7 & 88.5 & 7.9 & 20.6 & 8.5 & 54.9 & 7.5 & 47 \\
2-month & 26.1 & 9.9 & 65.4 & 15.0 & 22.6 & 11.4 & 67.1 & 11.8 & 21.8 & 11.4 & 66.5 & 10.0 & 33 \\
$\begin{array}{l}\text { maturity } \\
\text { 3-month } \\
\text { maturity }\end{array}$ & 26.7 & 10.7 & 63.7 & 15.6 & 22.1 & 10.9 & 64.1 & 11.9 & 22.3 & 10.7 & 63.0 & 12.7 & 24 \\
\hline
\end{tabular}

\subsection{Hypothesis and Analysis Framework}

Our hypotheses that the implied volatility estimated from the option price has the informative efficiency of realized volatility are as follows:

Hypothesis 1. Implied volatility $(I M V)$ has higher predictive power of future realized volatility $(F V)$ than historical volatility $(H V)$.

Hypothesis 2. Implied volatility contains all the information related to future realized volatility, and historical volatility does not have any information beyond that provided by implied volatility.

Hypothesis 3. The shorter the maturity, the higher is the predictive power of implied volatility.

Hypothesis 4. The predictive power of implied volatility endures regardless of market condition.

In this study, we use the following common regression models according to prior studies [17,41,42] to verify the above hypotheses.

$$
\begin{gathered}
M 1: F V_{t}=c+\gamma_{1} I M V_{t}+\varepsilon_{t} \\
M 2: F V_{t}=c+\gamma_{2} H V_{t}+\varepsilon_{t} \\
M 3: F V_{t}=c+\gamma_{3} I M V_{t}+\gamma_{4} H V_{t}+\varepsilon_{t}
\end{gathered}
$$


If the implied volatility of the KOSPI 200 index option has significant information about future realized volatility, then we should reject the null hypothesis of Equation (4), and if historical volatility has meaningful information about future realized volatility, then we should reject the null hypothesis of Equation (5).

$$
\begin{aligned}
& H_{0}: \gamma_{1}=0 \\
& H_{0}: \gamma_{2}=0
\end{aligned}
$$

To test Hypothesis 1, such that IMV has superior forecasting ability to $H V$, we can observe that the regression shown in Equation (1) has a larger adjusted R-squared value than that in Equation (2). To explore the relative importance of the information in the volatility estimates and their relative predictability considered in Hypothesis 2, we adopt the multiple regression shown in Equation (3) and examine whether $I M V$ should have a statistically significant and relatively larger coefficient than that of $H V$.

To test Hypothesis 3 regarding the maturity effects on the predictability, we also check whether the degree of support for Hypotheses 1 and 2 should differ as the option's maturity changes. Finally, to test Hypothesis 4 regarding the market condition's effects on predictability, we explore whether Hypotheses 1 and 2 are supported in all subsamples of the pre-crisis, crisis, and post-crisis periods.

Further, we checked whether implied volatility is an unbiased estimator of future realized volatility. Thereby, we performed Wald tests. F-test statistics for the joint hypothesis were $\mathrm{c}=0$ and $\gamma_{1}=1$ for Model 1; $\mathrm{c}=0$ and $\gamma_{2}=1$ for Model 2; and $\mathrm{c}=0, \gamma_{1}=1$, and $\gamma_{2}=0$ for Model 3 .

\section{Empirical Analysis}

\subsection{Results of Predictive Regressions}

Table 2 reports the coefficients, $t$-statistics (in parentheses), standard errors (in brackets), adjusted $R^{2}$ values, and F-test statistics of the predictive regressions of the future realized volatilities using monthly non-overlapping data of OTC index options. Standard errors were corrected by the Newey-West method. The independent variables are implied volatility (IMV) of near-the-money KOSPI 200 options and historical volatility (HV) for the past trading horizon of the average corresponding maturity of the selected options. The dependent variable is the realized volatility for the future trading horizon of the average corresponding maturity of the selected options.

Table 2. Predictability of the implied volatilities of over-the-counter (OTC) index options.

\begin{tabular}{cccccc}
\hline \multicolumn{6}{c}{ Panel A: One-Month Horizon } \\
\hline C & IMV & HV & adj. R & F-test \\
\hline M1 & 0.063 & 0.543 & & $65.1 \%$ & $61.03^{* * *}$ \\
& $(6.611)$ & $(17.921)$ & & & \\
& {$[0.010]$} & {$[0.030]$} & & & \\
M2 & 0.092 & & 0.507 & $56.1 \%$ & $30.73^{* * *}$ \\
& $(9.741)$ & & $(16.085)$ & & \\
& {$[0.009]$} & & {$[0.032]$} & & \\
M3 & 0.063 & 0.542 & 0.002 & $64.3 \%$ & $39.78^{* * *}$ \\
& $(6.69)$ & $(3.718)$ & $(0.011)$ & & \\
& {$[0.009]$} & {$[0.146]$} & {$[0.151]$} & & \\
\hline
\end{tabular}


Table 2. Cont.

\begin{tabular}{|c|c|c|c|c|c|}
\hline \multicolumn{6}{|c|}{ Panel B: Two-Month Horizon } \\
\hline & $\mathrm{C}$ & IMV & HV & adj. $R^{2}$ & F-test \\
\hline M1 & $\begin{array}{c}0.031 \\
(1.596) \\
{[0.020]}\end{array}$ & $\begin{array}{c}0.717 \\
(12.22) \\
{[0.587]}\end{array}$ & & $36.7 \%$ & $5.17^{* *}$ \\
\hline M2 & $\begin{array}{c}0.094 \\
(4.374) \\
{[0.022]}\end{array}$ & & $\begin{array}{c}0.549 \\
(11.171) \\
{[0.049]}\end{array}$ & $28.0 \%$ & $4.65^{* *}$ \\
\hline M3 & $\begin{array}{c}0.017 \\
(0.761) \\
{[0.022]} \\
\end{array}$ & $\begin{array}{c}0.996 \\
(2.630) \\
{[0.379]}\end{array}$ & $\begin{array}{c}-0.258 \\
(-0.826) \\
{[0.312]}\end{array}$ & $35.4 \%$ & $3.52 * *$ \\
\hline \multicolumn{6}{|c|}{ Panel C: Three-Month Horizon } \\
\hline & $\mathrm{C}$ & IMV & $\mathrm{HV}$ & adj. $R^{2}$ & F-test \\
\hline M1 & $\begin{array}{c}0.094 \\
(3.403) \\
{[0.028]}\end{array}$ & $\begin{array}{c}0.480 \\
(8.487) \\
{[0.057]}\end{array}$ & & $19.6 \%$ & $6.41^{* * *}$ \\
\hline M2 & $\begin{array}{c}0.130 \\
(4.032) \\
{[0.032]}\end{array}$ & & $\begin{array}{c}0.420 \\
(6.435) \\
{[0.653]}\end{array}$ & $14.6 \%$ & $4.70 * *$ \\
\hline M3 & $\begin{array}{c}0.090 \\
(3.55) \\
{[0.025]}\end{array}$ & $\begin{array}{c}0.599 \\
(2.337) \\
{[0.256]}\end{array}$ & $\begin{array}{c}-0.125 \\
(-0.463) \\
{[0.271]}\end{array}$ & $16.0 \%$ & $4.11^{* *}$ \\
\hline
\end{tabular}

Note: Newey-West $t$-statistics and associated standard errors are presented in parentheses and brackets, respectively. The $1 \%$ and $5 \%$ significance levels of the F-tests are denoted by ${ }^{* * *}$ and ${ }^{* *}$, respectively.

Panel A of Table 2 shows the regression model results for Equations (1) to (3) for the 1-month maturity. The results for Model 1, which verifies how the implied volatility observed in the OTC KOSPI 200 index option market explains the future actual volatility of KOSPI 200 index returns, show a strongly significant coefficient of implied volatility at the $1 \%$ level, and thus rejects the null hypothesis of Equation (4). The results for Model 2, which examines the predictive power of historical volatility, reject the null hypothesis of Equation (5) because the coefficient of historical volatility is also statistically significant at the same level. However, the magnitude and $t$-value of the coefficient of the implied volatility in Model 1 are greater than those of historical volatility in Model 2. The adjusted $R^{2}$ value of Model $1(65 \%)$ is larger than that of Model $2(56 \%)$. Therefore, we conclude that implied volatility has more predictive power than historical volatility.

The results for Model 3, in which we set implied and historical volatility as independent variables simultaneously, show that the coefficient of implied volatility is substantially significant, whereas that of the historical volatility is not substantially significant. This result indicates that implied volatility is likely to subsume the information incorporated in historical volatility in terms of predicting future realized volatility, which supports Hypothesis 2 . However, the adjusted $R^{2}$ of Model 3 is slightly less than that of Model 1, and the $t$-value of the implied volatility estimate is much less than that of Model 1; thus, Model 1 best explains future realized volatility.

Panel B of Table 2 shows the results of the predictive regression for future realized volatility for the 2-month maturity. The results for Model 1 strongly reject the null hypothesis of Equation (4) since implied volatility has a coefficient significance at the 1\% level. The results for Model 2 indicate significant estimates of historical volatility at the same level, which implies that historical volatility could also have meaningful information about future realized volatility. However, the results for Model 3 show that the coefficient of implied volatility is close to one and significant at the $1 \%$ level, while the significance of historical volatility disappears. Moreover, the adjusted $\mathrm{R}^{2}$ of Model 1 is the highest among the three models, at $37 \%$. Hence, the results indicate that implied volatility with the 2-month 
maturity tends to include more efficient information than historical volatility about the future volatility of stock returns; this is in line with the 1-month maturity results, which support Hypotheses 1 and 2.

Panel $\mathrm{C}$ of Table 2 reports the results of the predictive regression for the 3-month maturity. In Model 1, the implied volatility estimate is statistically significant at the $1 \%$ level, and in Model 2, the historical volatility estimate is significant at the same level. In Model 3, the coefficient of implied volatility is significant at the $5 \%$ level, while that of historical volatility is not significant. In addition, when we compare the explanatory power of the regressions, Model 1 is the best, at $20 \%$, though this value is much less than that for the 1-month maturity. Hence, the results support Hypothesis 1 , similar to the results for the 1- and 2-month maturities.

Further, in all the models across the different maturities, the F-test statistics reject the combined hypothesis of unbiasedness. Therefore, both implied and historical volatility are unlikely to be unbiased estimators of realized volatility, which is consistent with our result of a higher mean implied volatility than the mean realized volatility in Section 3.

In addition, when we compare the results for the different horizons, we find that the longer the maturity, the lower is the predictive power of implied volatility, which therefore supports Hypothesis 3. Intuitively, it is easier to predict the short-term than the long-term horizon. Thus, we expect that the implied volatility of options with shorter maturity has greater predictability. Some studies have empirically proved such maturity effect. For instance, Kang [43] analyzed the OTC KRW/USD currency option market and documented that the implied volatilities of options with 1- or 2-week maturities have explanatory power in forecasting future realized volatilities, while the implied volatilities of options with 3- or 4-weeks maturities do not have. Consistently with Kang's [43] result, our results provide evidence of the maturity effect in the prediction power of implied volatility.

In general, short-term maturity options are much more liquid. With high-frequency transaction data, Sim et al. [44] also support that short-term KOSPI200 options are more liquid in terms of bid/ask spreads and the number of transaction. Therefore, the decrease in the predictive power with maturity is not very surprising.

\subsection{Superior Predictive Power of Straddle Options}

As mentioned before, the volatility smile can bias the predictability of implied volatility and thus it will be nice to use the implied volatilities of at-the-money option prices when we examine the predictability of implied volatility. In Table 1, we find that most straddle options are quoted as at-the-money. Hence, to check robustness, we perform the same regressions using only straddle options.

Table 3 reports the coefficients, $t$-statistics (in parentheses), standard errors (in brackets), adjusted $R^{2}$ values, and F-test statistics of the predictive regressions of the future realized volatilities using the monthly OTC straddle options of the KOSPI 200 index. Standard errors were corrected by the Newey-West method. The non-overlapping data of the 1-, 2-, and 3-month maturities were constructed by selecting the straddle options with the longest maturity among options with $8 \sim 31(32 \sim 62,63 \sim 92)$ days to maturity at the earliest current day on each month, and then averaging the implied volatilities of the selected options for each month and generating the monthly (odd-monthly, quarterly) time series. The independent variables were the implied volatility (IMV) of the at-the-money straddle KOSPI 200 options and historical volatility (HV) for the past trading horizon of the average corresponding maturity of the selected straddle options. The dependent variable was the realized volatility for the future trading horizon of the average corresponding maturity of the selected straddle options.

Panel A of Table 3 shows the regression model results of straddle index options for Equations (1)-(3) for the 1-month maturity. The results for Model 1 indicate a strongly significant coefficient of implied volatility at the $1 \%$ level, rejecting the null hypothesis of Equation (4). When compared with the results of Panel A of Table 2, the magnitude of the coefficient is closer to one, 0.746, even though the $t$-value and the explanatory power of the regression are less than those of all types of options in Table 2. 
Table 3. Predictability of the implied volatilities of OTC straddle index options.

\begin{tabular}{|c|c|c|c|c|c|}
\hline \multicolumn{6}{|c|}{ Panel A: 1-Month Horizon } \\
\hline & $\mathrm{C}$ & IMV & HV & adj. $R^{2}$ & F-test \\
\hline M1 & $\begin{array}{c}0.026 \\
(1.525) \\
{[0.017]}\end{array}$ & $\begin{array}{c}0.746 \\
(10.336) \\
{[0.072]}\end{array}$ & & $58.6 \%$ & $13.50^{* * *}$ \\
\hline M2 & $\begin{array}{c}0.094 \\
(5.309) \\
{[0.018]}\end{array}$ & & $\begin{array}{c}0.536 \\
(5.644) \\
{[0.095]}\end{array}$ & $33.4 \%$ & $7.77^{* * *}$ \\
\hline M3 & $\begin{array}{c}0.025 \\
(1.292) \\
{[0.019]}\end{array}$ & $\begin{array}{c}0.928 \\
(5.813) \\
{[0.160]}\end{array}$ & $\begin{array}{c}-0.202 \\
(-1.537) \\
{[0.131]}\end{array}$ & $58.9 \%$ & $9.52^{* * *}$ \\
\hline \multicolumn{6}{|c|}{ Panel B: 2-Month Horizon } \\
\hline & $\mathrm{C}$ & IMV & HV & adj. $R^{2}$ & F-test \\
\hline M1 & $\begin{array}{c}0.041 \\
(1.758) \\
{[0.023]}\end{array}$ & $\begin{array}{c}0.727 \\
(10.931) \\
{[0.067]}\end{array}$ & & $38.0 \%$ & $2.72 *$ \\
\hline M2 & $\begin{array}{c}0.098 \\
(3.779) \\
{[0.026]}\end{array}$ & & $\begin{array}{c}0.550 \\
(11.262) \\
{[0.049]}\end{array}$ & $27.5 \%$ & $4.09 * *$ \\
\hline M3 & $\begin{array}{c}0.002 \\
(0.03) \\
{[0.027]}\end{array}$ & $\begin{array}{c}1.646 \\
(2.665) \\
{[0.617]}\end{array}$ & $\begin{array}{c}-0.835 \\
(-1.556) \\
{[0.536]}\end{array}$ & $41.3 \%$ & $2.76^{*}$ \\
\hline \multicolumn{6}{|c|}{ Panel C: 3-Month Horizon } \\
\hline & $\mathrm{C}$ & IMV & HV & adj. $R^{2}$ & F-test \\
\hline M1 & $\begin{array}{c}0.091 \\
(3.359) \\
{[0.027]}\end{array}$ & $\begin{array}{c}0.522 \\
(7.727) \\
{[0.068]}\end{array}$ & & $17.6 \%$ & $3.57 * *$ \\
\hline M2 & $\begin{array}{c}0.132 \\
(4.119) \\
{[0.032]}\end{array}$ & & $\begin{array}{c}0.405 \\
(6.553) \\
{[0.617]}\end{array}$ & $14.0 \%$ & $5.14^{* *}$ \\
\hline M3 & $\begin{array}{c}0.061 \\
(1.302) \\
{[0.047]}\end{array}$ & $\begin{array}{c}1.048 \\
(1.125) \\
{[0.931]}\end{array}$ & $\begin{array}{c}-0.459 \\
(-0.584) \\
{[0.786]}\end{array}$ & $15.1 \%$ & $2.42 *$ \\
\hline
\end{tabular}

Note: Newey-West $t$-statistics and associated standard errors are presented in parentheses and brackets, respectively. The $1 \%, 5 \%$, and $10 \%$ significance levels of the F-tests are denoted by ${ }^{* * *}, * *$, and $*$, respectively.

The results for Model 2 reject the null hypothesis of Equation (5) because the coefficient of historical volatility is also statistically significant at the same level. However, the magnitude and the $t$-value of the coefficient of implied volatility in Model 1 are much greater than those of the historical volatility in Model 2. The adjusted $\mathrm{R}^{2}$ value of Model 1 (59\%) is higher than that of Model $2(33 \%)$. Thus, the results indicate that the implied volatility of straddle options is superior to historical volatility in predicting future volatility.

The results for Model 3 indicate that the coefficient of implied volatility is significant, whereas that of historical volatility is not significant. This result suggests that implied volatility should subsume the information reflected in historical volatility in forecasting future realized volatility, thus supporting Hypothesis 2. Moreover, it is noticeable that the magnitude of coefficient is near to one, 0.928 , and the adjusted $\mathrm{R}^{2}$ of Model 3 is almost the same as that of Model 1, even though the $t$-value of the implied volatility estimate is much lower than that of Model 1. Therefore, Model 3 as well as Model 1 for straddle options with 1-month maturity could be preferred to capture future realized volatility.

Panel B of Table 3 shows the results of the predictive regression of future realized volatility on the implied volatilities of OTC straddle index options for the 2-month maturity. The implied volatility has a coefficient significant at the 1\% level and thus the null hypothesis of Equation (4) is rejected. The results 
for Model 2 show a significant estimate of historical volatility at the same level, but the adjusted $\mathrm{R}^{2}$ is the smallest of the three models, at $28 \%$. The results for Model 3 indicate that the coefficient of implied volatility is significant at the $1 \%$ level, while the significance of historical volatility disappears. Therefore, the results indicate that the implied volatility of straddle options with the 2-month maturity is likely to capture future volatility information more effectively than historical volatility, which does not reject Hypotheses 1 and 2.

Panel $\mathrm{C}$ of Table 3 reports the results of the predictive regression of the implied volatility of straddle options for the 3-month maturity. In Model 1, the implied volatility coefficient is statistically significant at the $1 \%$ level, and in Model 2, the historical volatility coefficient is significant at the same level. On the other hand, in Model 3, both coefficients are not significant. In addition, when we compare the explanatory power of the regressions, Model 1 is the best, at $18 \%$, though the value is much less than that for the 1-month maturity. Hence, these results support Hypothesis 1, similar to the results for the 1- and 2-month maturities.

Moreover, in all models across different maturities, the F-test statistics reject the combined hypothesis of unbiasedness at the $10 \%$ significance level. Hence, both the implied volatility of straddle options and historical volatility tend to be biased estimators of realized volatility, which is consistent with our result for all types of options in Table 2. Further, we confirm that the shorter the maturity, the higher is the predictive power of the implied volatility, when the results for the different maturities of the at-the-money straddle options are compared.

\subsection{Robustness Tests}

We replace historical volatility with a volatility forecast under the GARCH $(1,1)$ model in Model 3 and checked the robustness as in Table 4. The $t$-statistics (in parentheses) and standard errors (in brackets) are also presented. Standard errors were corrected by the Newey-West method. We discovered that the coefficients of GARCH volatility (GV) are mostly not significant. It is only for straddle options with 2-month maturity that the coefficient of GARCH volatility is negative and significant at the $5 \%$ level, but that of implied volatility is positive and more highly significant at the $5 \%$ level. Hence, we confirm that the outperformance of implied volatility endures even after using a volatility forecast under a GARCH-type model instead of historical volatility across all maturities, both in all types of options and in straddle options taken separately.

Table 4. Robustness test: GARCH volatility effect.

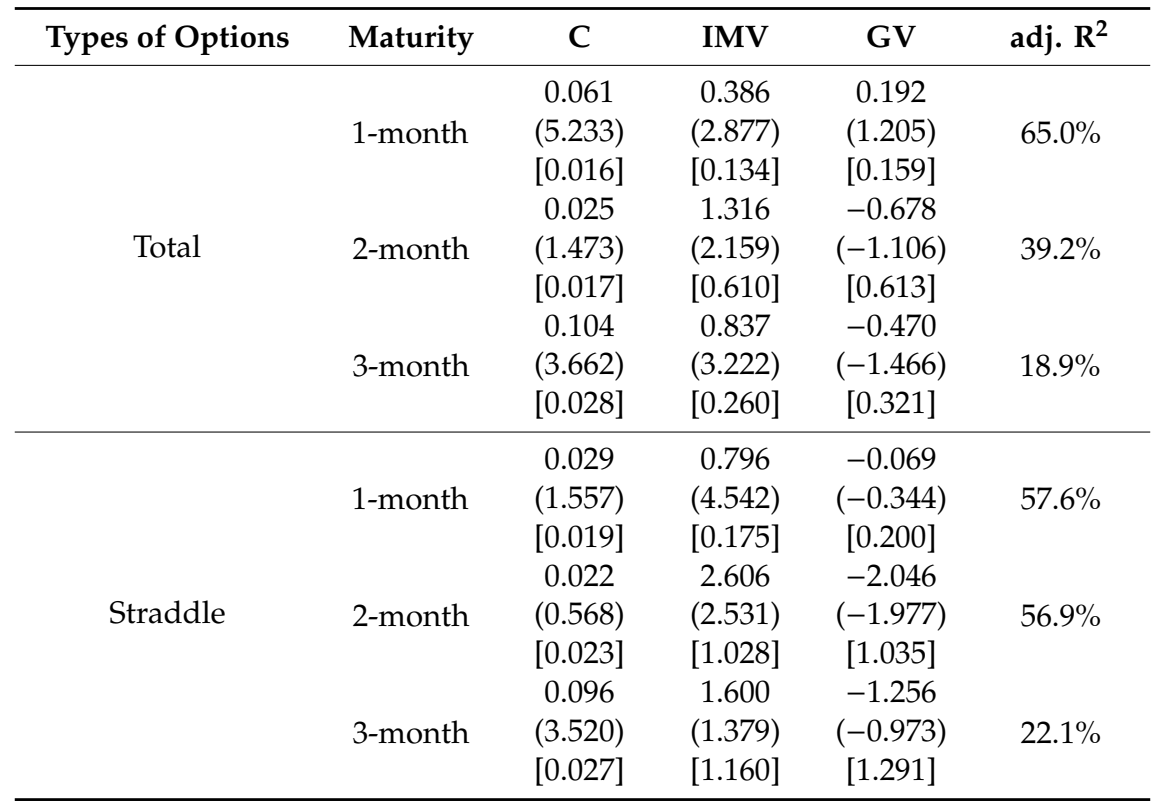

Note: Newey-West $t$-statistics and associated standard errors are presented in parentheses and brackets, respectively. 
Another robustness check is related to the effect of variance risk premiums (VRP). It is well known that option-implied volatility exceeds the $\mathrm{HV}$ of the underlying assets because of a risk premium for future uncertainty of volatility $[45,46]$. In other words, VRP can be defined as the difference between IMV and HV; i.e., $V R P=I M V-H V$. In the previous section, the main result shows that IMV has a stronger predictive power for FV than HV. Next, we examine whether the additional prediction comes from VRP or whether there is any pure information conveyed solely by IMV. To this end, in Table 5 we repeat the same analysis as Table 4 with VRP as an explanatory variable. As earlier, the $t$-statistics (in parentheses), standard errors (in brackets), and adj- $\mathrm{R}^{2} \mathrm{~s}$ (in the last column) are also presented. Standard errors were corrected by the Newey-West method.

The result in Table 5 shows that VRP is insignificant for predicting FV regardless of control variables, test options, and forecasting horizons. The only exception is the one-month prediction with the control of GV. The $t$-statistic is 2.92 for the case where all options are used and 4.15 for the case where straddle options are used. However, the control variable GV, which is a proxy of historical volatility, is even more significant than VRP, and most of the adj- $R^{2}$ of those regressions comes from GV. Univariate regressions with VRP show adj- $R^{2} s$ of $0.3 \%$ and $3 \%$ for the case of all options and the case of straddles, respectively. The reason that VRP becomes significant when GV is used in Panel A is because of a high correlation between GV and short-term HV; recall that VRP is the difference between IMV and HV. The estimation of GV puts more weight on recent data and short-term HV is more correlated with GV. Therefore, when we use three-month horizon VRP (IMV with three-month maturity minus HV with past three-month data), only GV is significant.

This finding suggests that the stronger predictive power of IMV is not a result of VRP. IMV conveys unique information about FV, which suggests that OTC options market participants have more information or sophisticated skills for predicting the future volatility of underlying assets.

Table 5. Robustness test: variance risk premiums (VRP) effect.

\begin{tabular}{|c|c|c|c|c|c|}
\hline \multicolumn{6}{|c|}{ Panel A: One-Month Horizon } \\
\hline Types of Options & $\mathrm{C}$ & VRP & GV & VIX & adj. $R^{2}$ \\
\hline \multirow{12}{*}{ Total } & 0.195 & 0.281 & & & $0.3 \%$ \\
\hline & $(10.131)$ & $(1.567)$ & & & \\
\hline & [0.019] & [0.179] & & & \\
\hline & 0.048 & 0.396 & 0.629 & & $66.5 \%$ \\
\hline & $(3.658)$ & $(2.922)$ & $(12.431)$ & & \\
\hline & {$[0.013]$} & {$[0.136]$} & {$[0.051]$} & & \\
\hline & 0.062 & 0.063 & & 0.617 & $42.9 \%$ \\
\hline & $(2.341)$ & $(0.387)$ & & $(4.646)$ & \\
\hline & [0.027] & {$[0.164]$} & & [0.133] & \\
\hline & 0.046 & 0.379 & 0.605 & 0.037 & $65.8 \%$ \\
\hline & $(3.345)$ & $(2.429)$ & $(7.244)$ & $(0.372)$ & \\
\hline & [0.014] & {$[0.156]$} & [0.083] & [0.099] & \\
\hline \multirow{12}{*}{ Straddle } & 0.194 & 0.410 & & & $3 \%$ \\
\hline & $(13.88)$ & $(1.887)$ & & & \\
\hline & {$[0.014]$} & {$[0.217]$} & & & \\
\hline & -0.008 & 0.731 & 0.898 & & $60 \%$ \\
\hline & $(-0.282)$ & $(4.149)$ & $(7.38)$ & & \\
\hline & [0.029] & {$[0.176]$} & [0.122] & & \\
\hline & 0.069 & 0.224 & & 0.568 & $40 \%$ \\
\hline & $(3.7)$ & (2.443) & & (8.026) & \\
\hline & [0.019] & [0.092] & & [0.071] & \\
\hline & -0.009 & 0.755 & 0.934 & -0.034 & $58.8 \%$ \\
\hline & $(-0.338)$ & (3.192) & $(4.089)$ & $(-0.212)$ & \\
\hline & {$[0.026]$} & [0.237] & [0.228] & [0.159] & \\
\hline
\end{tabular}


Table 5. Cont.

\begin{tabular}{|c|c|c|c|c|c|}
\hline \multicolumn{6}{|c|}{ Panel B: Two-Month Horizon } \\
\hline Types of Options & $\mathrm{C}$ & VRP & GV & VIX & adj. $R^{2}$ \\
\hline \multirow{12}{*}{ Total } & 0.222 & -0.091 & & & $-3.1 \%$ \\
\hline & $(5.43)$ & $(-0.205)$ & & & \\
\hline & [0.041] & {$[0.445]$} & & & \\
\hline & 0.034 & 0.648 & 0.729 & & $24.6 \%$ \\
\hline & $(1.331)$ & $(2.185)$ & $(13.967)$ & & \\
\hline & {$[0.026]$} & {$[0.297]$} & {$[0.052]$} & & \\
\hline & 0.090 & 0.357 & & 0.516 & $23.1 \%$ \\
\hline & $(4.265)$ & $(1.184)$ & & $(8.761)$ & \\
\hline & {$[0.021]$} & [0.301] & & [0.059] & \\
\hline & 0.047 & 0.567 & 0.461 & 0.221 & $23.2 \%$ \\
\hline & $(1.525)$ & $(2.032)$ & $(1.848)$ & $(1.114)$ & \\
\hline & [0.031] & [0.279] & {$[0.249]$} & [0.198] & \\
\hline \multirow{12}{*}{ Straddle } & 0.223 & 0.077 & & & $-3.5 \%$ \\
\hline & $(5.974)$ & $(0.132)$ & & & \\
\hline & [0.037] & [0.583] & & & \\
\hline & 0.037 & 1.007 & 0.746 & & $26.2 \%$ \\
\hline & $(1.479)$ & (1.87) & (12.6) & & \\
\hline & [0.058] & [0.618] & [0.213] & & \\
\hline & 0.100 & 0.457 & & 0.491 & $20.8 \%$ \\
\hline & (5.438) & (0.891) & & (8.651) & \\
\hline & [0.018] & [0.513] & & [0.057] & \\
\hline & 0.037 & 1.000 & 0.734 & 0.009 & $23.4 \%$ \\
\hline & (1.873) & (1.788) & $(2.948)$ & $(0.043)$ & \\
\hline & {$[0.02]$} & [0.559] & [0.249] & [0.215] & \\
\hline
\end{tabular}

Panel C: Three-Month Horizon

\begin{tabular}{|c|c|c|c|c|c|}
\hline Types of Options & $\mathrm{C}$ & VRP & GV & VIX & $\operatorname{adj.} R^{2}$ \\
\hline \multirow{12}{*}{ Total } & 0.208 & 0.305 & & & \multirow[t]{3}{*}{$-3.1 \%$} \\
\hline & (6.126) & $(0.986)$ & & & \\
\hline & [0.034] & [0.309] & & & \\
\hline & 0.094 & 0.499 & 0.475 & & \multirow[t]{2}{*}{$24.6 \%$} \\
\hline & (2.964) & (1.888) & (6.982) & & \\
\hline & [0.032] & {$[0.264]$} & [0.068] & & \multirow{3}{*}{$23.1 \%$} \\
\hline & 0.144 & 0.216 & & 0.314 & \\
\hline & $(5.96)$ & $(0.698)$ & & $(3.048)$ & \\
\hline & [0.024] & {$[0.31]$} & & [0.103] & \multirow{4}{*}{$23.2 \%$} \\
\hline & 0.085 & 0.619 & 0.654 & -0.167 & \\
\hline & (1.989) & $(2.08)$ & (1.694) & $(-0.516)$ & \\
\hline & [0.043] & [0.298] & [0.386] & [0.325] & \\
\hline \multirow{12}{*}{ Straddle } & 0.234 & -0.414 & & & \multirow[t]{3}{*}{$-3.5 \%$} \\
\hline & (7.644) & $(-0.762)$ & & & \\
\hline & [0.031] & {$[0.544]$} & & & \\
\hline & 0.076 & 0.594 & 0.588 & & \multirow{2}{*}{$26.2 \%$} \\
\hline & (2.278) & $(0.857)$ & $(4.75)$ & & \\
\hline & [0.033] & [0.693] & [0.124] & & \multirow{4}{*}{$20.8 \%$} \\
\hline & 0.152 & 0.029 & & 0.323 & \\
\hline & $(4.756)$ & $(0.047)$ & & (2.118) & \\
\hline & [0.032] & [0.623] & & [0.153] & \\
\hline & 0.074 & 0.608 & 0.613 & -0.021 & \multirow[t]{3}{*}{$23.4 \%$} \\
\hline & (1.618) & $(0.832)$ & (1.461) & $(-0.065)$ & \\
\hline & [0.046] & [0.73] & {$[0.42]$} & {$[0.32]$} & \\
\hline
\end{tabular}

Note: Newey-West $t$-statistics and associated standard errors are presented in parentheses and brackets, respectively. 
Furthermore, previous studies $[47,48]$ report that the US VIX plays an important role in determining the market volatility dynamics in the Korean market. Thus, we should check whether the predictability of implied volatility is robust even after adding the VIX as an independent variable. Table A2 shows the regression results of Model 3 after controlling for the VIX.

We find that the variable VIX is mostly not a critical predictor both in all types of options and in straddle options taken separately. It is only for straddle options with 1-month and 2-month maturities that the coefficients of VIX are negatively significant at the $10 \%$ and $5 \%$ level, respectively. However, the coefficients of implied volatility are significant at the $1 \%$ level and positive, which is consistent with our prediction. Therefore, we confirm that the results in Tables 2 and 3 are not very different even after controlling for the VIX. As shown in Table 5 earlier, the VIX is significant.

\section{Effect of the Financial Crisis}

One of our research questions is whether the predictability of implied volatility is different depending on the market conditions (related to Hypothesis 4). Since our sample period involves the global financial crisis period, we can check whether severe market conditions can affect the predictability of implied volatility of the OTC options market. Thus, we try to perform predictive regressions for three subsamples-the pre-crisis, crisis, and post-crisis periods. In this regard, daily overlapping data of the index options are inevitably used since there is insufficient non-overlapping data for each sub-period. In addition, we find that 1-month maturity options have better predictive ability than 2-month or 3-month options, as seen in Table 3, and thus we use 1-month maturity options in the following analysis.

Table 6 reports the coefficients, $t$-statistics (in parentheses), standard errors (in brackets), and adjusted $R^{2}$ values of the predictive regressions of the future realized volatilities using daily overlapping data of OTC index options with 1-month maturity (8 31 days to maturity). Overlapping data of 1-month maturity was constructed by selecting options with the longest maturity from the options with 8 31 days to maturity on each day, and then averaging the implied volatilities of the selected options across different strike prices for each day and generating the daily time series.

Table 6. Predictive regression for the pre-crisis, crisis, and post-crisis periods.

\begin{tabular}{|c|c|c|c|c|c|c|}
\hline \multicolumn{7}{|c|}{ Panel A: Pre-Crisis Period } \\
\hline Types of Options & Model & $\mathrm{C}$ & IMV & HV & adj. $R^{2}$ & $\mathbf{N}$ \\
\hline \multirow{9}{*}{ Total } & \multirow{3}{*}{ M1 } & 0.081 & 0.424 & & $36.0 \%$ & \multirow{9}{*}{33} \\
\hline & & (3.207) & $(4.356)$ & & & \\
\hline & & [0.025] & [0.097] & & \multirow{4}{*}{$35.9 \%$} & \\
\hline & \multirow{6}{*}{ M3 } & 0.096 & & 0.408 & & \\
\hline & & $(4.371)$ & & $(4.347)$ & & \\
\hline & & [0.022] & & [0.094] & & \\
\hline & & 0.079 & 0.234 & 0.222 & $37.7 \%$ & \\
\hline & & (3.186) & (1.383) & $(1.366)$ & & \\
\hline & & [0.025] & [0.169] & [0.163] & & \\
\hline \multirow{9}{*}{ Straddle } & \multirow{3}{*}{ M1 } & 0.034 & 0.664 & & \multirow[t]{3}{*}{$55.6 \%$} & \multirow{9}{*}{25} \\
\hline & & $(1.247)$ & $(5.568)$ & & & \\
\hline & & [0.027] & [0.119] & & & \\
\hline & & 0.103 & & 0.380 & $35.0 \%$ & \\
\hline & M2 & $(4.502)$ & & $(3.734)$ & & \\
\hline & & [0.023] & & [0.102] & \multirow{4}{*}{$54.0 \%$} & \\
\hline & \multirow{3}{*}{ M3 } & 0.029 & 0.755 & -0.074 & & \\
\hline & & $(0.988)$ & $(3.234)$ & $(-0.452)$ & & \\
\hline & & [0.03] & [0.233] & {$[0.165]$} & & \\
\hline
\end{tabular}


Table 6. Cont.

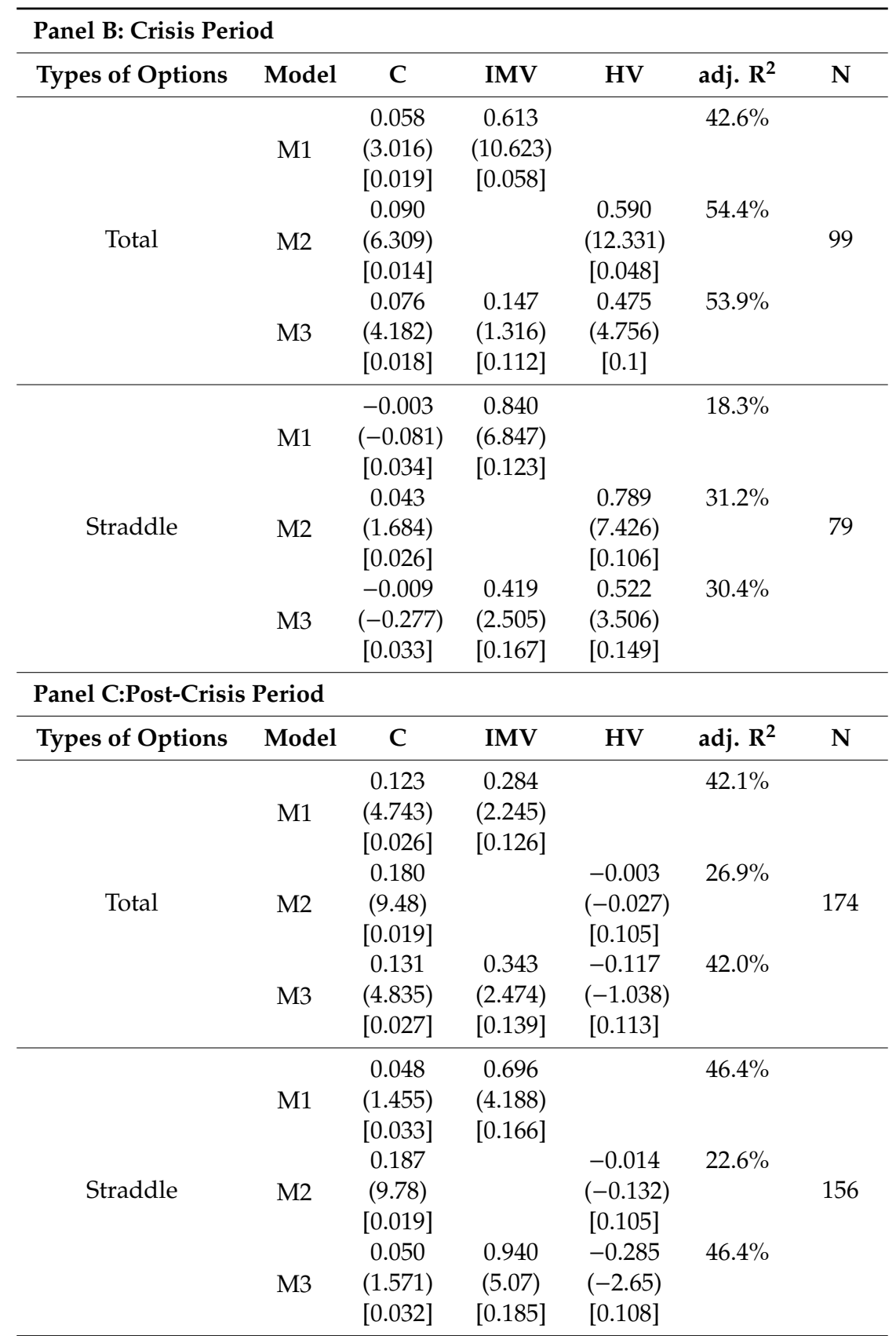

Note: Newey-West $t$-statistics and associated standard errors are presented in parentheses and brackets, respectively.

One independent variable, implied volatility (IMV), was estimated from near-the-money KOSPI 200 call, put, and straddle options, with 1-month maturity for the total and is estimated from at-the-money KOSPI 200 straddle options with 1-month maturity for straddle. The historical volatility $(\mathrm{HV})$, the other independent variable, and realized volatility, the dependent variable, are measured by the same method as illustrated in Table 2.

Panel A, B, and C show the results for the subsamples pre-crisis, crisis, and post-crisis periods, respectively. Although there is no clear consensus on the period of the recent financial crisis [49-52], Kim et al. [50] suggest a sophisticated method to determine the crisis period and perform a volatility break test with the information of credit default swap spreads. Following Kim et al. [50], we define the end of crisis period as follows: the pre-crisis period spans from March 2005 to December 2007, the crisis 
period spans from January 2008 to August 2009, and the post-crisis period spans from September 2009 to April 2011. The last column reports the number $(\mathrm{N})$ of time-series data for each type of option.

Panel A of Table 6 shows the regression results of OTC stock index options during the pre-crisis period. For all types of options, the results for Model 1 show a substantially significant estimate of implied volatility at the $1 \%$ level and the results for Model 2 show that the estimate of historical volatility is also statistically significant at the same level. However, the magnitude and the $t$-value of the coefficient of implied volatility in Model 1 are a slightly greater than those of historical volatility in Model 2. The results for Model 3 show that the coefficients of both implied volatility and historical volatility are not significant. Thus, Model 1 is appropriate for predicting realized volatility during the pre-crisis period.

For straddle options, the results for Model 1 and Model 2 are similar to those for all types of options. The magnitude and the $t$-value of the coefficient of the implied volatility in Model 1 are much greater than those of historical volatility in Model 2. In addition, the results for Model 3 show that only the implied volatility estimate is significant. However, the adjusted $R^{2}$ value of Model $1(56 \%)$ is higher than that of Model 3 (54\%). Thus, for straddle options, Model 1 is appropriate for forecasting realized volatility during the pre-crisis period, which is consistent with the results for all types of options.

Further, similar results are found for the post-crisis period of Panel C of Table 6. For all types of options, the results for Model 1 show a significant coefficient of implied volatility at the $5 \%$ level and the results for Model 2 show non-significant coefficient of historical volatility. The results for Model 3 also show that the estimate of implied volatility is significant, whereas that of historical volatility is not substantially significant. The adjusted $\mathrm{R}^{2}$ values of Model $1(42.1 \%)$ are almost similar to those of Model 3 (42\%). This result implies that historical volatility has no incremental information beyond that conveyed by implied volatility during the post-crisis period.

For straddle options, the results for Model 1 show a significant coefficient of implied volatility at the $1 \%$ level. The results for Model 2 show that the estimate of historical volatility is not statistically significant. The results for Model 3 also show that the estimate of implied volatility is substantially significant, whereas that of historical volatility is significant but negative.

In contrast, striking results are found for the crisis period of Panel B of Table 6. Both for all types of options and for straddle options taken separately, the results for Model 1 show a significant estimate of implied volatility at the $1 \%$ level. The results for Model 2 also show that the estimate of historical volatility is substantially significant at the same level, and the $t$-value of the coefficient of historical volatility in Model 2 is much higher than that of implied volatility in Model 1. The results for Model 3 show that the estimate of historical volatility is strongly significant, whereas that of implied volatility is not strongly significant or less significant. This result implies that historical volatility is superior to implied volatility in explaining future realized volatility during the crisis period.

To better understand the reason why the predictability of historical volatility outperforms that of implied volatility during the crisis period, we examine the bid-ask spread. Figure 1 depicts the time series of the cross-sectional average bid-ask spread of implied volatilities of KOSPI 200 index options in the OTC market. The solid lines in the upper graph are the time series of the cross-sectional average bid-ask spread of implied volatilities for all types of options, while the solid lines in the lower graph are those for straddle options.

In Figure 1, we see that the bid-ask spreads of all types of options are larger than those of straddle options over the entire sample period; that is, the liquidity of the straddle options is higher than that of the call and put options. This phenomenon explains why straddle options have superior predictability than all types of options, as shown in Tables 2 and 3.

Meanwhile, it should be noted that the bid-ask spreads of implied volatility severely spike during the crisis period to about $10 \%$, which indicate the liquidity contraction of the options market. We can observe this phenomenon in both graphs. Moreover, we have already found that the predictability disappears both in all types of options and in straddle options taken separately, only during the crisis period in Table 6 . Therefore, our analysis of bid-ask spreads supports our conjecture that the 
liquidity problem in the options market is the main reason why the predictability of implied volatility underperforms than that of historical volatility during the crisis period.

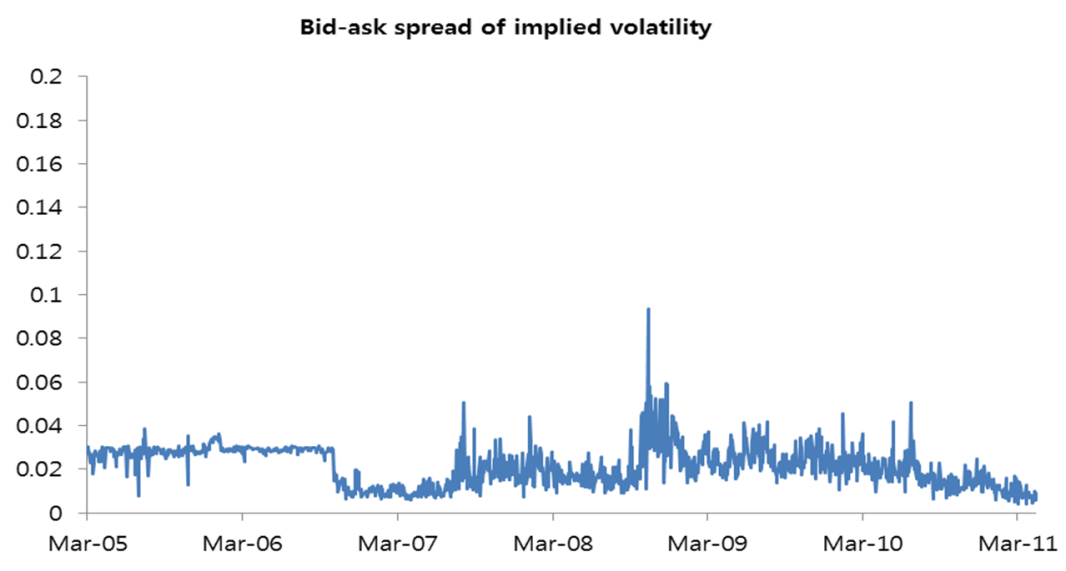

(a)

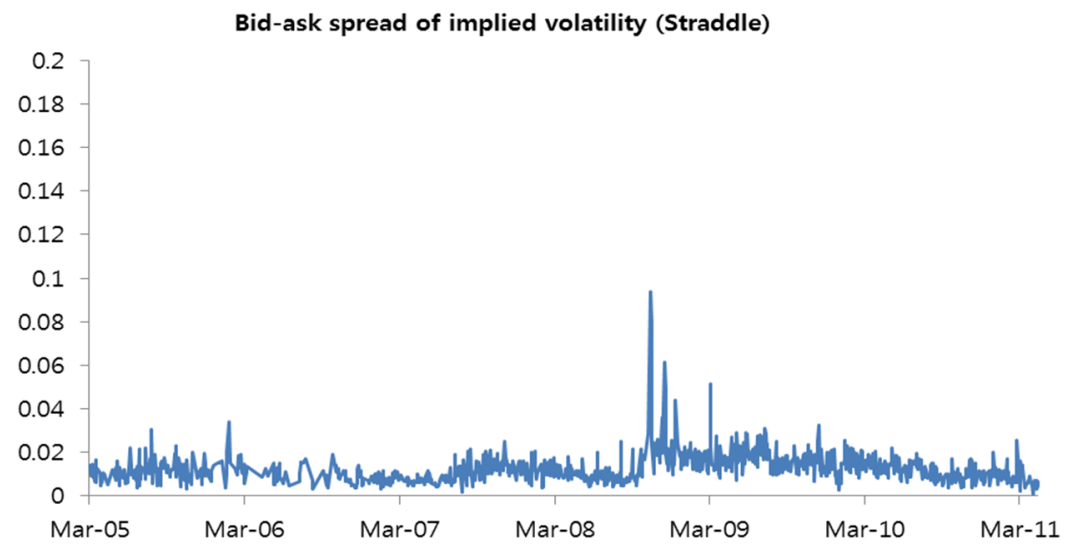

(b)

Figure 1. Time series of the cross-sectional average bid-ask spread of implied volatilities of KOSPI200 index options in the OTC market. (a) all types of options; (b) straddle options.

\section{Exchange-Traded Options}

One limitation of our study is that the data used is too old and the conclusion is difficult to be generalized to the recent date. To overcome this limitation, we repeated the main analysis with exchange-traded options data covering the 2003-2019 period. We use VKOSPI as a proxy of implied volatility (IMV). VKOSPI is the volatility index of the Korean options market, which is computed by using the implied volatility of KOSPI200 options in a similar way as the VIX. For monthly frequency regressions, month-end observations of VKOSPI were used. Historical volatility (HV) was computed by the standard deviation of daily return of the KOSPI200 index multiplied by $\sqrt{252}$ to annualize it. Future volatility (FV) is one-month-ahead observation of the HV. With this setting, we ran the main regressions (1)-(3).

Table 7 presents the regression result for the entire sample period. Newey-West $t$-statistics were computed. With the sample of exchange-traded options, we confirm that the main findings of the OTC market remain the same. While both HV and IMV are statistically significant for predicting FV, IMV outperforms HV in terms of the magnitude of coefficient, statistical significance, and adjusted $R^{2}$. 
Table 7. Predictive regression with exchange-traded options: entire period.

\begin{tabular}{cccc}
\hline & M1 & M2 & M3 \\
\hline CONST & $4.85^{* * *}$ & 1.20 & $2.10^{* * *}$ \\
& $(6.51)$ & $(1.42)$ & $(2.07)$ \\
HV & $0.72^{* * *}$ & & $0.30^{* * *}$ \\
& $(16.63)$ & & $(2.32)$ \\
IMV & & $0.79^{* * *}$ & $0.49^{* * *}$ \\
& & $(17.15)$ & $(3.38)$ \\
Adj R & 0.51 & 0.53 & 0.54 \\
N & 203 & 203 & 203
\end{tabular}

Note: Newey-West $t$-statistics are presented in parentheses. $\mathrm{N}$ denotes the number of months in the sample. Significance at the $1 \%$ and $5 \%$ level is indicated by $* * *$ and $* *$, respectively.

The sub-sample analysis presented in Table 8 provides more interesting implications. As we defined earlier, the financial crisis period is from January 2008 to August 2009. In the rest of the entire sample period, the pre- and post-crisis periods are before and after the crisis period. While the main empirical analysis suffers from the lack of data on OTC options, the exchange data allows us to analyze more recent periods. Interestingly, we confirm the underperformance of IMV during the financial crisis period, which is observed in the OTC options market.

Table 8. Predictive regression with exchange-traded options for sub-sample periods.

\begin{tabular}{|c|c|c|c|}
\hline & M1 & M2 & M3 \\
\hline \multicolumn{4}{|c|}{ Panel A: Pre-Crisis (January 2003-December 2007) } \\
\hline CONST & $\begin{array}{c}9.67 \\
(5.45)\end{array}$ & $\begin{array}{c}2.47 \\
(1.58)\end{array}$ & $\begin{array}{c}3.09 \\
(1.60)\end{array}$ \\
\hline $\mathrm{HV}$ & $\begin{array}{c}0.53 \\
(7.44)\end{array}$ & & $\begin{array}{c}0.14 \\
(0.87)\end{array}$ \\
\hline IMV & & $\begin{array}{c}0.77 \\
(11.85)\end{array}$ & $\begin{array}{c}0.62 \\
(3.11)\end{array}$ \\
\hline $\operatorname{Adj} R^{2}$ & 0.27 & 0.34 & 0.33 \\
\hline $\mathrm{N}$ & 60 & 60 & 60 \\
\hline \multicolumn{4}{|c|}{ Panel B: Crisis (January 2008-August 2009) } \\
\hline CONST & $\begin{array}{c}9.74 \\
(2.96)\end{array}$ & $\begin{array}{c}6.70 \\
(1.56)\end{array}$ & $\begin{array}{l}15.33 \\
(2.25)\end{array}$ \\
\hline $\mathrm{HV}$ & $\begin{array}{c}0.66 \\
(11.81)\end{array}$ & & $\begin{array}{c}1.16 \\
(3.17)\end{array}$ \\
\hline IMV & & $\begin{array}{c}0.66 \\
(10.64)\end{array}$ & $\begin{array}{c}-0.59 \\
(-1.31)\end{array}$ \\
\hline $\operatorname{Adj} R^{2}$ & 0.39 & 0.29 & 0.38 \\
\hline $\mathrm{N}$ & 20 & 20 & 20 \\
\hline \multicolumn{4}{|c|}{ Panel C: Post-Crisis (September 2009-December 2019) } \\
\hline CONST & $\begin{array}{c}5.47 \\
(4.71)\end{array}$ & $\begin{array}{c}0.37 \\
(0.20)\end{array}$ & $\begin{array}{c}1.42 \\
(1.09)\end{array}$ \\
\hline $\mathrm{HV}$ & $\begin{array}{c}0.60 \\
(5.80)\end{array}$ & & $\begin{array}{c}0.24 \\
(1.32)\end{array}$ \\
\hline IMV & & $\begin{array}{c}0.82 \\
(6.20)\end{array}$ & $\begin{array}{c}0.56 \\
(3.52)\end{array}$ \\
\hline $\operatorname{Adj} R^{2}$ & 0.35 & 0.39 & 0.40 \\
\hline $\mathrm{N}$ & 123 & 123 & 123 \\
\hline
\end{tabular}

Note: Newey-West $t$-statistics are presented in parentheses. $\mathrm{N}$ denotes the number of months in the sample.

At normal times, such as the pre- and post-crisis periods, while both HV and IMV are significant predictors of FV in the univariate regressions (M1 and M2), IMV absorbs the economical and statistical significance of the HV in the bivariate regression (M3). In contrast, during the financial crisis, 
HV outperforms IMV and absorbs the significance of the IMV, suggesting that option-implied volatility does not convey additional information about future spot volatility. This result supports our discussion about the underperformance of IMV during the financial crisis in the previous section. Therefore, the main findings in the previous sections are not restricted to the specific period of 2005-2011.

\section{Conclusions}

Utilizing non-overlapping data for the OTC KOSPI 200 index options, we analyzed the predictability of implied volatility for the OTC stock index option market, which has rarely been studied in the literature. This study contributes to the stream of research on the OTC options market by providing evidence consistent with prior findings on the efficiency of OTC stock index options. In addition, our study enriches the literature by reporting the maturity effect and discovering that the implied volatility of options with shorter maturities are clearly superior to historical volatility in predicting future volatility. Furthermore, we provide evidence that the implied volatility of OTC stock index options loses its predictive ability during the global financial crisis period, while it has substantially significant predictability during the pre- and post-crisis periods. The main reason for this is that there is liquidity contraction in the OTC options market during the crisis and, thus, historical volatility has superiority in explaining future realized volatility.

Implied volatility is regarded as a common prediction of the options market of future volatility to the option expiration date. If the options market is efficient, the implied volatility will reflect all the information that explains future volatility. Thus, our study analyzes whether the OTC KOSPI 200 index options market is efficient and present the following implications. First, if liquidity in the options market can be sufficient, the outperformance of predictability endures in the long run. Secondly, for the establishment and execution of sophisticated portfolio insurance strategies and asset allocation strategies, accurate prediction of future volatility is very important. In addition, estimates of volatility are also used in risk management or in developing new financial products. Thus, as long as market participants continue to perform these activities, the options' implied volatility, which is a superior forecast of future volatility, will continue to be required and, therefore, options can be regarded as a sustainable asset.

Financial markets enable the real economy to create additional value by providing funds to the real economy. For example, firms are funded from stock and bond markets and stock and bond investors are rewarded by dividend, interest, and capital gains from firms. Without sustainable investment in financial assets, such as stocks and bonds, firms lose the opportunity for growth, and thus negatively affect the real economy. In contrast, the collapse of the real economy deteriorates the stability of finance. Hence, sustainable finance can be obtained by actively circulating cash flows between the financial markets and the real economy.

Financial derivatives, such as futures and options, had emerged for the stability of finance by managing the risks of traditional assets, such as stocks and bonds. With the recent massive development of financial derivatives markets, financial derivatives also contain information regarding forecasting risks of traditional assets. Therefore, understanding the information content in option volatility on future stock volatility in this study can help investors make better decisions based on more accurate measures of risks and contribute to sustainable finance. Moreover, as our study is mainly based on scientific methodologies to analyze information and content, it contributes to sustainability science.

Our study has the following limitations. First, as mentioned earlier, several institutions have recently provided quotes for OTC stock options; however, we used data from only one institution who offered data from the early days. Therefore, there is a need to collect data from all institutions and check the robustness of our results. Secondly, we calculated the realized volatility as a proxy for future spot volatility. However, we can also consider the square root of the realized future variance of a variance swap. This alternative proxy should be examined in another study. Finally, when we split the sample into three subsamples to explore the effect of a financial crisis, we cannot use non-overlapping 
data because the non-overlapping data for each sub-period are insufficient. Thus, the results should be rechecked when non-overlapping data are sufficiently available.

Moreover, future research can be performed as follows. To determine which component of the implied volatility has forecasting ability, we must decompose the implied volatility into the expected future volatility and the volatility risk premium, which is defined by the implied volatility minus the expected future volatility. Analysis concerning the predictability of the expected future volatility and volatility risk premium on return and cash flow growth can also give market participants more advanced and sophisticated information and contribute to sustainability science.

Author Contributions: The authors contributed to this paper as follows. J.K.: methodology, validation, writing-review and editing, supervision; Y.J.P.: software, formal analysis, investigation, data curation, writing-original draft preparation. All authors have read and agreed to the published version of the manuscript.

Funding: This research was supported by the Hallym University Research Fund, HRF-202003-006.

Conflicts of Interest: The authors declare no conflict of interest.

\section{Appendix A}

Table A1. Characteristics of the KOSPI200 index options quoted in the OTC market.

\begin{tabular}{|c|c|c|c|c|c|c|c|}
\hline \multicolumn{8}{|c|}{ Panel A: Number of Quotes } \\
\hline \multirow[b]{2}{*}{ Types of Options } & \multirow[b]{2}{*}{ Exercise Price (\%) } & \multicolumn{6}{|c|}{ Days to Maturity } \\
\hline & & $8-31$ & $32-62$ & $63-92$ & 93-184 & $185-366$ & $>=367$ \\
\hline \multirow{13}{*}{ Call } & $50-59$ & & & & & & 1 \\
\hline & $80-89$ & & & & & & 1 \\
\hline & 90-99 & & 2 & & 373 & 714 & \\
\hline & 100-109 & 18 & 213 & 201 & 761 & 903 & 143 \\
\hline & $110-119$ & 15 & 145 & 248 & 1019 & 1081 & 192 \\
\hline & $120-129$ & 1 & 17 & 54 & 239 & 174 & 143 \\
\hline & 130-139 & & 2 & 15 & 54 & 106 & 106 \\
\hline & $140-149$ & & & 6 & 14 & 34 & 79 \\
\hline & 150-159 & & & 1 & 3 & 18 & 73 \\
\hline & $160-169$ & & & & & 3 & 18 \\
\hline & $170-179$ & & & & & & 9 \\
\hline & 180-189 & & & & & & 5 \\
\hline & 200-209 & & & & & & 7 \\
\hline \multirow{10}{*}{ Put } & $20-29$ & & & & & & 1 \\
\hline & $30-39$ & & & & & 2 & 2 \\
\hline & $40-49$ & & & & & 1 & 8 \\
\hline & $50-59$ & & & 2 & 10 & 24 & 48 \\
\hline & $60-69$ & & & 9 & 42 & 116 & 113 \\
\hline & $70-79$ & 1 & 10 & 46 & 183 & 181 & 90 \\
\hline & $80-89$ & 4 & 60 & 161 & 449 & 316 & 295 \\
\hline & 90-99 & 67 & 379 & 455 & 1244 & 1250 & 328 \\
\hline & 100-109 & 11 & 28 & 46 & 451 & 785 & 50 \\
\hline & 110 & & & & 381 & 726 & \\
\hline \multirow{3}{*}{ Straddle } & 90-99 & & 9 & 5 & 5 & 10 & \\
\hline & 100-109 & 231 & 694 & 579 & 1018 & 1290 & 1620 \\
\hline & 110-119 & & & & & & 1 \\
\hline Total & & 348 & 1559 & 1828 & 6246 & 7734 & 3333 \\
\hline
\end{tabular}


Table A1. Cont.

\begin{tabular}{|c|c|c|c|c|c|c|c|}
\hline \multicolumn{8}{|c|}{ Panel B: Average Implied Volatility } \\
\hline \multirow[b]{2}{*}{ Types of Options } & \multirow[b]{2}{*}{ Exercise Price (\%) } & \multicolumn{6}{|c|}{ Days to Maturity } \\
\hline & & $8-31$ & $32-62$ & $63-92$ & 93-184 & $185-366$ & $>=367$ \\
\hline \multirow{13}{*}{ Call } & $50-59$ & & & & & & 0.437 \\
\hline & $80-89$ & & & & & & 0.266 \\
\hline & $90-99$ & & 0.290 & & 0.229 & 0.222 & \\
\hline & $100-109$ & 0.216 & 0.208 & 0.198 & 0.201 & 0.205 & 0.192 \\
\hline & $110-119$ & 0.290 & 0.263 & 0.240 & 0.208 & 0.198 & 0.204 \\
\hline & $120-129$ & 0.321 & 0.360 & 0.291 & 0.262 & 0.235 & 0.223 \\
\hline & $130-139$ & & 0.435 & 0.420 & 0.306 & 0.249 & 0.213 \\
\hline & 140-149 & & & 0.427 & 0.338 & 0.280 & 0.239 \\
\hline & 150-159 & & & 0.459 & 0.468 & 0.281 & 0.246 \\
\hline & $160-169$ & & & & & 0.352 & 0.239 \\
\hline & 170-179 & & & & & & 0.269 \\
\hline & 180-189 & & & & & & 0.293 \\
\hline & $200-209$ & & & & & & 0.347 \\
\hline \multirow{10}{*}{ Put } & $20-29$ & & & & & & 0.484 \\
\hline & $30-39$ & & & & & 0.568 & 0.487 \\
\hline & $40-49$ & & & & & 0.451 & 0.441 \\
\hline & $50-69$ & & & 0.702 & 0.666 & 0.494 & 0.341 \\
\hline & $60-69$ & & & 0.626 & 0.496 & 0.378 & 0.323 \\
\hline & $70-79$ & 0.582 & 0.531 & 0.426 & 0.372 & 0.330 & 0.293 \\
\hline & $80-89$ & 0.492 & 0.369 & 0.333 & 0.313 & 0.296 & 0.268 \\
\hline & $90-99$ & 0.326 & 0.273 & 0.270 & 0.249 & 0.244 & 0.240 \\
\hline & 100-109 & 0.221 & 0.227 & 0.237 & 0.216 & 0.222 & 0.242 \\
\hline & 110 & & & & 0.193 & 0.202 & \\
\hline \multirow{3}{*}{ Straddle } & 90-99 & & 0.173 & 0.173 & 0.180 & 0.184 & \\
\hline & 100-109 & 0.234 & 0.229 & 0.226 & 0.230 & 0.230 & 0.234 \\
\hline & 110-119 & & & & & & 0.249 \\
\hline Total & & 0.257 & 0.249 & 0.257 & 0.238 & 0.230 & 0.241 \\
\hline
\end{tabular}

Table A2. The predictive regressions after controlling for the US VIX.

\begin{tabular}{|c|c|c|c|c|c|c|}
\hline Types of Options & Maturity & C & IMV & HV & VIX & $\operatorname{adj} . R^{2}$ \\
\hline \multirow{9}{*}{ Total } & \multirow{3}{*}{ 1-month } & 0.059 & 0.512 & 0.004 & 0.047 & \multirow{3}{*}{$63.6 \%$} \\
\hline & & $(2.901)$ & $(2.776)$ & $(0.025)$ & $(0.334)$ & \\
\hline & & {$[0.02]$} & [0.185] & [0.163] & {$[0.14]$} & \\
\hline & \multirow{3}{*}{ 2-month } & 0.012 & 1.080 & -0.213 & -0.122 & \multirow{3}{*}{$33.6 \%$} \\
\hline & & $(0.223)$ & (2.094) & $(-0.504)$ & $(-0.406)$ & \\
\hline & & [0.053] & [0.516] & {$[0.423]$} & [0.301] & \\
\hline & \multirow{3}{*}{ 3-month } & 0.077 & 1.134 & -0.086 & -0.631 & \multirow{3}{*}{$20.0 \%$} \\
\hline & & $(1.364)$ & $(1.818)$ & $(-0.175)$ & $(-1.424)$ & \\
\hline & & {$[0.056]$} & {$[0.624]$} & [0.49] & {$[0.443]$} & \\
\hline \multirow{9}{*}{ Straddle } & \multirow{4}{*}{ 1-month } & 0.042 & 0.909 & -0.215 & -0.394 & \multirow{3}{*}{$61.3 \%$} \\
\hline & & $(1.589)$ & (4.993) & $(-1.263)$ & $(-1.795)$ & \\
\hline & & [0.026] & [0.251] & [0.178] & [0.173] & \\
\hline & & -0.055 & 2.878 & -1.099 & -0.828 & \multirow{3}{*}{$50.1 \%$} \\
\hline & \multirow[t]{2}{*}{ 2-month } & $(-1.05)$ & (3.815) & $(-2.219)$ & $(-2.397)$ & \\
\hline & & {$[0.053]$} & {$[0.754]$} & [0.495] & {$[0.345]$} & \\
\hline & \multirow{3}{*}{ 3-month } & 0.056 & 1.259 & -0.464 & -0.219 & \multirow{3}{*}{$12.5 \%$} \\
\hline & & $(0.701)$ & $(1.262)$ & $(-0.583)$ & $(-0.618)$ & \\
\hline & & [0.079] & [0.998] & [0.795] & [0.355] & \\
\hline
\end{tabular}




\section{References}

1. Awartani, B.M.A.; Corradi, V. Predicting the volatility of the S\&P-500 stock index via GARCH models: The role of asymmetries. Int. J. Forecast. 2005, 21, 167-183. [CrossRef]

2. Blair, B.J.; Poon, S.-H.; Taylor, S.J. Modelling S\&P 100 volatility: The information content of stock returns. J. Bank. Finance 2001, 25, 1665-1679. [CrossRef]

3. Chen, A.-S. Forecasting the S\&P 500 index volatility. Int. Rev. Econ. Finance 1997, 6, 391-404. [CrossRef]

4. Gospodinov, N.; Gavala, A.; Jiang, D. Forecasting volatility. J. Forecast. 2006, 25, 381-400. [CrossRef]

5. Perry, P.R. The time-variance relationship of security returns: Implications for the return-generating stochastic process. J. Financ. 1982, 37, 857-870. [CrossRef]

6. Pagan, A.R.; Schwert, G.W. Alternative models for conditional stock volatility. J. Econ. 1990, 45, $267-290$. [CrossRef]

7. Engle, R.F. Autoregressive conditional heteroscedasticity with estimates of the variance of United Kingdom inflation. Econometrica 1982, 50, 987-1007. [CrossRef]

8. Bollerslev, T. Generalized autoregressive conditional heteroskedasticity. J. Econ. 1986, 31, 307-327. [CrossRef]

9. Chakravarty, S.; Gulen, H.; Mayhew, S. Informed trading in stock and option markets. J. Financ. 2004, 59, 1235-1257. [CrossRef]

10. Ni, S.X.; Pan, J.; Poteshman, A.M. Volatility information trading in the option market. J. Financ. 2008, 63, 1059-1091. [CrossRef]

11. Hu, J. Does option trading convey stock price information? J. Financ. Econ. 2014, 111, 625-645. [CrossRef]

12. Christensen, B.J.; Prabhala, N.R. The relation between implied and realized volatility. J. Financ. Econ. 1998, 50, 125-150. [CrossRef]

13. Fleming, J. The quality of market volatility forecasts implied by S\&P 100 index option prices. J. Empir. Financ. 1998, 5, 317-345. [CrossRef]

14. Blair, B.J.; Poon, S.-H.; Taylor, S.J. Forecasting S\&P 100 volatility: The incremental information content of implied volatilities and high-frequency index returns. J. Econ. 2001, 105, 5-26. [CrossRef]

15. Giot, P. The information content of implied volatility in agricultural commodity markets. J. Futur. Mark. 2003, 23, 441-454. [CrossRef]

16. Black, F.; Scholes, M. The pricing of options and corporate liabilities. J. Political Econ. 1973, 81, 637-654. [CrossRef]

17. Yu, W.W.; Lui, E.C.K.; Wang, J.W. The predictive power of the implied volatility of options traded OTC and on exchanges. J. Bank. Financ. 2010, 34, 1-11. [CrossRef]

18. Valaskova, K.; Kliestik, T.; Svabova, L.; Adamko, P. Financial Risk Measurement and Prediction Modelling for Sustainable Development of Business Entities Using Regression Analysis. Sustainability 2018, 10, 2144. [CrossRef]

19. Park, Y.J.; Kutan, A.M.; Ryu, D. The impacts of overseas market shocks on the CDS-option basis. N. Am. J. Econ. Finance 2019, 47, 622-636. [CrossRef]

20. Covrig, V.; Low, B.S. The quality of volatility traded on the over-the-counter currency market: A multiple horizons study. J. Futures Mark. 2003, 23, 261-285. [CrossRef]

21. Park, Y.J.; Kim, T.S. The information content of OTC individual put option implied volatility for credit default swap spreads. Asia Pac. J. Financ. Stud. 2012, 41, 491-516. [CrossRef]

22. Deuskar, P.; Gupta, A.; Subrahmanyam, M.G. Liquidity effect in OTC options markets: Premium or discount? J. Financ. Mark. 2011, 14, 127-160. [CrossRef]

23. Chalamandaris, G.; Tsekrekos, A.E. Predictable dynamics in implied volatility surfaces from OTC currency options. J. Bank. Financ. 2010, 34, 1175-1188. [CrossRef]

24. Manaster, S.; Rendleman, R.J. Option prices as predictors of equilibrium stock prices. J. Financ. 1982, 37, 1043-1057. [CrossRef]

25. Doran, J.S.; Peterson, D.R.; Tarrant, B.C. Is there information in the volatility skew? J. Futur. Mark. 2007, 27, 921-959. [CrossRef]

26. Jorion, P. Predicting volatility in the foreign exchange market. J. Financ. 1995, 50, 507-528. [CrossRef]

27. Busch, T.; Christensen, B.J.; Nielsen, M.Ø. The role of implied volatility in forecasting future realized volatility and jumps in foreign exchange, stock, and bond markets. J. Econom. 2011, 160, 48-57. [CrossRef] 
28. Taylor, S.J.; Yadav, P.K.; Zhang, Y. The information content of implied volatilities and model-free volatility expectations: Evidence from options written on individual stocks. J. Bank. Financ. 2010, 34, 871-881. [CrossRef]

29. Xing, Y.; Zhang, X.; Zhao, R. What does the individual option volatility smirk tell us about future equity returns? J. Financ. Quant. Anal. 2010, 45, 641-662. [CrossRef]

30. Bekaert, G.; Hoerova, M. The VIX, the variance premium and stock market volatility. J. Econ. 2014, 183, 181-192. [CrossRef]

31. Yun, J. A re-examination of the predictability of stock returns and cash flows via the decomposition of VIX. Econ. Lett. 2020, 186, 108755. [CrossRef]

32. Luo, X.; Qin, S.; Ye, Z. The information content of implied volatility and jumps in forecasting volatility: Evidence from the Shanghai gold futures market. Financ. Res. Lett. 2016, 19, 105-111. [CrossRef]

33. Jung, Y.C. Relative performance of VIXC vs. GARCH in predicting realised volatility changes. Invest. Anal. J. 2016, 45, S1-S16. [CrossRef]

34. Ahn, H.-J.; Kang, J.; Ryu, D. Informed trading in the index option market: The case of KOSPI 200 options. J. Futur. Mark. 2008, 28, 1118-1146. [CrossRef]

35. Ryu, D.; Yang, H. Who has volatility information in the index options market? Finance Res. Lett. 2018, 30, 266-270. [CrossRef]

36. Kim, J.S.; Ryu, D. Are the KOSPI 200 implied volatilities useful in value-at-risk models? Emerg. Mark. Rev. 2015, 22, 43-64. [CrossRef]

37. Kang, J.; Park, H.-J. The information content of net buying pressure: Evidence from the KOSPI 200 index option market. J. Financ. Mark. 2008, 11, 36-56. [CrossRef]

38. Chun, D.; Cho, H.; Ryu, D. Forecasting the KOSPI200 spot volatility using various volatility measures. Phys. Stat. Mech. Its Appl. 2019, 514, 156-166. [CrossRef]

39. Cao, C.; Yu, F.; Zhong, Z. The information content of option-implied volatility for credit default swap valuation. J. Financ. Mark. 2010, 13, 321-343. [CrossRef]

40. Becker, R.; Clements, A.E.; White, S.I. Does implied volatility provide any information beyond that captured in model-based volatility forecasts? J. Bank. Finance 2007, 31, 2535-2549. [CrossRef]

41. Harvey, C.R.; Whaley, R.E. Market volatility prediction and the efficiency of the S \& P 100 index option market. J. Financ. Econ. 1992, 31, 43-73. [CrossRef]

42. Szakmary, A.; Ors, E.; Kyoung Kim, J.; Davidson, W.N. The predictive power of implied volatility: Evidence from 35 futures markets. J. Bank. Financ. 2003, 27, 2151-2175. [CrossRef]

43. Kang, B.J. Information content of implied volatilities in KRW/USD currency option markets. Korean J. Future Opt. 2011, 19, 207-232.

44. Sim, M.; Ryu, D.; Yang, H. Tests on the monotonicity properties of KOSPI 200 options prices. J. Futures Mark. 2016, 36, 625-646. [CrossRef]

45. Bollerslev, T.; Tauchen, G.; Zhou, H. Expected stock returns and variance risk premia. Rev. Financ. Stud. 2009, 22, 4463-4492. [CrossRef]

46. Carr, P.; Wu, L. Variance risk premiums. Rev. Financ. Stud. 2009, 22, 1311-1341. [CrossRef]

47. Song, W.; Ryu, D.; Webb, R.I. Overseas market shocks and VKOSPI dynamics: A Markov-switching approach. Financ. Res. Lett. 2016, 16, 275-282. [CrossRef]

48. Song, W.; Ryu, D.; Webb, R.I. Volatility dynamics under an endogenous Markov-switching framework: A cross-market approach. Quant. Finance 2018, 18, 1559-1571. [CrossRef]

49. Corò, F.; Dufour, A.; Varotto, S. Credit and liquidity components of corporate CDS spreads. J. Bank. Financ. 2013, 37, 5511-5525. [CrossRef]

50. Kim, T.S.; Park, Y.J.; Noh, J. The linkage between the options and credit default swap markets during the subprime mortgage crisis. J. Futures Mark. 2013, 33, 518-554. [CrossRef]

51. Galil, K.; Shapir, O.M.; Amiram, D.; Ben-Zion, U. The determinants of CDS spreads. J. Bank. Financ. 2014, 41, 271-282. [CrossRef]

52. Tang, D.Y.; Yan, H. Understanding transactions prices in the credit default swaps market. J. Financ. Mark. 2017, 32, 1-27. [CrossRef]

(C) 2020 by the authors. Licensee MDPI, Basel, Switzerland. This article is an open access article distributed under the terms and conditions of the Creative Commons Attribution (CC BY) license (http://creativecommons.org/licenses/by/4.0/). 